\title{
Hybrid Power System Sizing and Design for Commercial Application in Kenya
}

\author{
Leonard Kipyegon Rotich ${ }^{1 *}$, Joseph Kamau ${ }^{2}$, Jared Ndeda ${ }^{2}$, Robert Kinyua ${ }^{2}$ \\ ${ }^{1}$ Institute for Energy \& Environmental Technology, Jomo Kenyatta University of Agriculture \& Technology, \\ P.O. Box 62000-00200, Nairobi. \\ ${ }^{2}$ Department of Physics, Jomo Kenyatta University of Agriculture \& Technology, \\ P.O. Box 62000, Nairobi, Kenya
}

* Corresponding Authar email: kipyegonleon@yahoo.com

Article History

Received: 10 June 2018

Revised: 31 August 2018

Accepted: 01 October 2018

Published: 01 October 2018

Student(s)

- $\quad$ Leonard Kipyegon Rotich

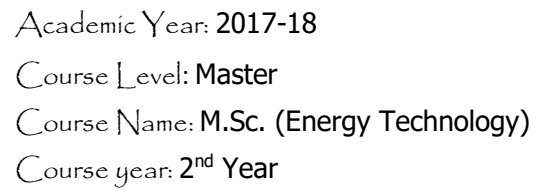

\begin{abstract}
Hybrid power system sizing involves determination of local load and energy resources' conditions as well as availability of generating system components. Each component of the system is preliminarily sized individually using prevailing load, resource and conversion system's conditions. The Net Present Cost (NPC), Cost of Energy (COE) may be included in determining the configuration of the most optimal system that can meet all the desired power system's goals. In order to refine the sizing and design process, a simulation software is used to select and size system components that can serve the load effectively. In this study, a Solar PV, Wind and Grid hybrid power system was systematically sized to meet the demand of a commercial consumer, East African School of Aviation (EASA). HOMER software was used to simulate the operation of the proposed HPS. The most suitable HPS was found to consist of Wind generation of an installed capacity of $200 \mathrm{~kW}$, solar PV of 120 $\mathrm{kW}$ and the Grid. This system had an NPC of KSh 77,684,050 and a COE of KSh 8.34/kWh.
\end{abstract}

Keyword: Hybrid Power System, Net Present Cost, Cost of energy, wind energy, solar PV, Simulation.

\section{Introduction}

Hybrid Power System (HPS) is a power system composed of more than one generator for serving a common load. HPS sizing is a process that leads to coming up with a power system that meets most or all of the requirements of a load [1]. Sizing involves defining of operation environment including constraints of a power system. The critical system constraints that are defined during system sizing include; lifespan of entire system and components, fraction of the load requirement that must be met as well as the system costs [1]. To accurately size individual components of a hybrid system, simulation of system under real operating conditions like prevailing weather, insolation, wind speed and load is necessary for a more realistic result [2]-[3]. Site weather 
conditions like insolation and wind speeds are determined by carrying out resource assessment in order to quantify their existing potential. The load conditions are similarly assessed to establish its distribution relative to local energy resources availability.

Load assessment involves finding details such as peak load, base load and the general trends. Load trends can be categorized for week days, weekends and seasons if variations exist. Categorization of loads into fixed and deferable loads further improves system sizing outcome [3]-[4]. Finding the exact load to be served is quite problematic due to erratic human behavior in using electrical appliances. Load data measured over a short period of time can be used to synthesize yearly load data in order to simulate annual operation of a HPS. Finding the optimal hybrid system is often a multi-objective problem of minimizing costs, maximizing energy resource utilization, ensuring power quality, stability and acceptable level of security [2]. Levelized Cost of energy (LCOE) and Net Present Cost (NPC) are economic indicators that can be used in system selection to achieve minimum system cost [4]. Based on preset economic indicators such as interest rate, inflation rate and technological constrains such as allowable demand shortfall and emission factor, the most optimal system that matches the desirable operating conditions is selected [5].

Power systems that utilize renewable energy resources like solar and wind suffer from intermittency hence storage would be required in order to get continuous supply of power from them. Hybrid power systems are designed to fully or partly overcome weaknesses such as variability of individual resources by leveraging on their complementarity [6]. The dispatch strategy of hybrid power is based on power system energy balance and load sharing. When one source is not available, the demand is met by the combined generation of available resources according to their capacity [6].

\subsection{Hybrid Power System Components}

In this section, a review of hybrid system components is done in order to highlight their theoretical framework. Emphasis is given to wind, Solar and grid for they are the constituent components of the hybrid system reviewed for the case study.

\subsubsection{Solar energy}

Abundant natural resource the world over, but more so in Kenya because of her position. Kenya lies within the equator and does enjoy long hours of sunshine throughout the year across the whole country [7]. From resource potential perspective therefore, Solar can form a significant component of a hybrid system in any location of the country. The amount of solar radiation in a location determines the extend of solar power utilization to meet a project's objectives. Both the quality and quantity of local energy resource potential is useful in the decision making to deploy a particular power system to meet demand [8] Solar Power System components are designed and selected by considering the periodic variation in insolation, Operating characteristics of solar harnessing device and the demand features of the load to be served [9]

\subsubsection{Solar PV}

The most common solar PV technology in use today is the silicon PN-junction solar cell. Several solar cells may be connected in series and in parallel to increase voltage and current output respectively. Output from a PV system is dependent on the amount of radiation incident on its surface. The variation of incident radiation from the Sun during the day and across the yearly seasons influence the productivity of a PV system. A mathematical equation containing significant parameters for power output from a PV system is given by Equation 1 [10].

$$
P_{\text {solar }}=P_{S T C} f_{P V}\left(\frac{G_{T}}{G_{S T C}}\right)\left\lfloor 1+a_{p}\left(T_{C}-T_{S T C}\right)\right\rfloor
$$


Where $P_{\text {STC }}$ is power from PV panels at standard test conditions, $f_{P V}$ is derating factor, $G_{T}\left(W / m^{2}\right)$ is the incident radiation, $\mathrm{G}_{\mathrm{STC}}\left(\mathrm{W} / \mathrm{m}^{2}\right)$ is radiation in standard test conditions $\left(1000 \mathrm{~W} / \mathrm{m}^{2}\right)$, $a_{\mathrm{p}}$ is the temperature coefficient which influence PV system performance according to the real time temperature of the system and $\mathrm{T}_{\mathrm{C}}$ is the PV cell temperature.

\subsubsection{Wind energy}

Wind energy is converted to electricity by means of wind turbines and electric generators. Wind turbines convert winds kinetic energy to turbines rotational power. The rotating shaft of a wind turbine is coupled to an electric generator which gives an AC output. There are two types of wind turbines in use today, horizontal axis wind turbines (HAW'T) and vertical axis wind turbines (VAW'T). Horizontal axis wind turbines have their rotational axis parallel to direction of wind flow and the ground.

The power in the wind is given by the Equation 3 [11]

$$
P=\frac{1}{2} \rho \mathrm{A} v^{3}
$$

Where $\varrho\left(\mathrm{kg} / \mathrm{m}^{3}\right)$ is the density of air, $\mathrm{A}\left(\mathrm{m}^{2}\right)$ is the rotor swept area and $\mathrm{v}$ is wind velocity.

It is not possible to convert all the power in the wind into a wind turbine kinetic energy but only a fraction of it is. Albert Betz established that the theoretical maximum efficiency (power coefficient) of any wind turbine design is 59\% [11]. This is known as The Betz limit or Betz law. It is therefore necessary to factor in the power coefficient in Equation 3 so that the extractable power from the wind is given by Equation 3.

$$
P_{\text {avail }}=\frac{1}{2} \rho \mathrm{A} v^{3} C_{p}
$$

The power in the wind over a long period during which a wind turbine will be used to generate power may be estimated through statistical methods. A probability density function $(\mathrm{f}(\mathrm{v}))$ which indicates the fraction of time for which the wind speed is at a given velocity $V$ and is expressed in Equation 4 [12];

$$
f(v)=k / c[v / c]^{k-1} e^{-\left(\frac{v}{c}\right)^{k}}
$$

Where; $\mathrm{k}$ is the shape factor, $\mathrm{c}$ is the scale factor and $\mathrm{V}$ is the wind speed.

Cumulative distribution function $\mathrm{F}(\mathrm{V})$ which indicates the time fraction or the probability that the wind speed is equals to or less than $\mathrm{V}$ is the integral of the probability density function described by Equation 4 .

$$
F(v)=\int_{0}^{v} f(v) d v=1-e^{-\left(\frac{v}{c}\right)^{k}}
$$

\section{Methodology}

In order to carry out this study, a suitable site (East African School of aviation, EASA) for carrying out HPS sizing was selected and all the vital parameters obtained for analysis. Data for power usage and trends were measured onsite while solar and wind resources potential were obtained from NASA Surface Meteorological data base for the site under review. System costs for installing and operating the HPS were included for purposes of estimating important economic indicators that were used in establishing the viability of the system. Load conditions of the site were determined by recording power consumption data using a power energy meter with logging capabilities at time intervals of 5 minutes over a period of one month. The collected load data was analyzed to get an average hourly consumption in order to get a typical daily load profile. The daily load profile was then used to generate a yearly synthetic load to be met by an HPS using local energy resources of solar and wind. Local energy resource potential for solar and wind were obtained from NASA surface meteorological data base for location at coordinates (- 1.314013, 36.903924) which represent EASA. Monthly average wind speed data for a Typical Meteorological Year (TMY) was obtained for anemometer height of $50 \mathrm{~m}$ and analyzed 
to get wind regime conditions at wind generator hub height of $30 \mathrm{~m}$. Daily average solar insolation was similarly obtained and used to generate hourly irradiance to correspond to load intervals. Both load and resource data were used to select and size a suitable HPS for the site.

\section{Results and Discussion}

An excerpt of the power consumption data that was collected using a power data logger is shown in Table 1.

Table 1: Power consumption data at the site

\begin{tabular}{|l|l|l|l|l|l|}
\hline Date & Time & Voltage $\left(\mathbf{V}_{\text {avg }}\right)$ & Current, Iavg $(A)$ & Real Power (W) & Real Energy (Wh) \\
\hline $11 / 24 / 2017$ & $12: 42: 51$ & 249.43 & 124.96 & 90450.43 & -14618716 \\
\hline $11 / 24 / 2017$ & $12: 47: 51$ & 250.83 & 126.52 & 91674.77 & -14611192 \\
\hline $11 / 24 / 2017$ & $12: 52: 51$ & 251.02 & 140.98 & 103430.1 & -14603614 \\
\hline $11 / 24 / 2017$ & $12: 57: 51$ & 248.83 & 135.49 & 98587.13 & -14595218 \\
\hline $11 / 24 / 2017$ & $13: 02: 51$ & 250.35 & 129.7 & 94448.41 & -14587176 \\
\hline $11 / 24 / 2017$ & $13: 07: 51$ & 247.74 & 141.88 & 103346.3 & -14578985 \\
\hline $11 / 24 / 2017$ & $13: 12: 51$ & 247.05 & 136.99 & 99381.61 & -14570356 \\
\hline $11 / 24 / 2017$ & $13: 17: 51$ & 247.33 & 127.08 & 91247.47 & -14562390 \\
\hline $11 / 24 / 2017$ & $13: 22: 51$ & 247.84 & 134.12 & 96881.11 & -14554542 \\
\hline $11 / 24 / 2017$ & $13: 27: 51$ & 247.2 & 135.05 & 97413.31 & -14546640 \\
\hline $11 / 24 / 2017$ & $13: 32: 51$ & 247.9 & 126.78 & 91965.19 & -14538470 \\
\hline $11 / 24 / 2017$ & $13: 37: 51$ & 247.26 & 102.87 & 75325.89 & -14531234 \\
\hline $11 / 24 / 2017$ & $13: 42: 50$ & 246.44 & 107.42 & 78244.73 & -14524650 \\
\hline $11 / 24 / 2017$ & $13: 47: 51$ & 245.72 & 114.56 & 83325.7 & -14517888 \\
\hline & & & & & \\
\hline & & & & & \\
\hline & & & & & \\
\hline & & & & & \\
\hline & & & & & \\
\hline
\end{tabular}

A typical day load profile was determined by calculating hourly average power usage for the site studied. It was observed that peak usage occurred between $7 \mathrm{am}$ and $5 \mathrm{pm}$ as shown in Figure 1.

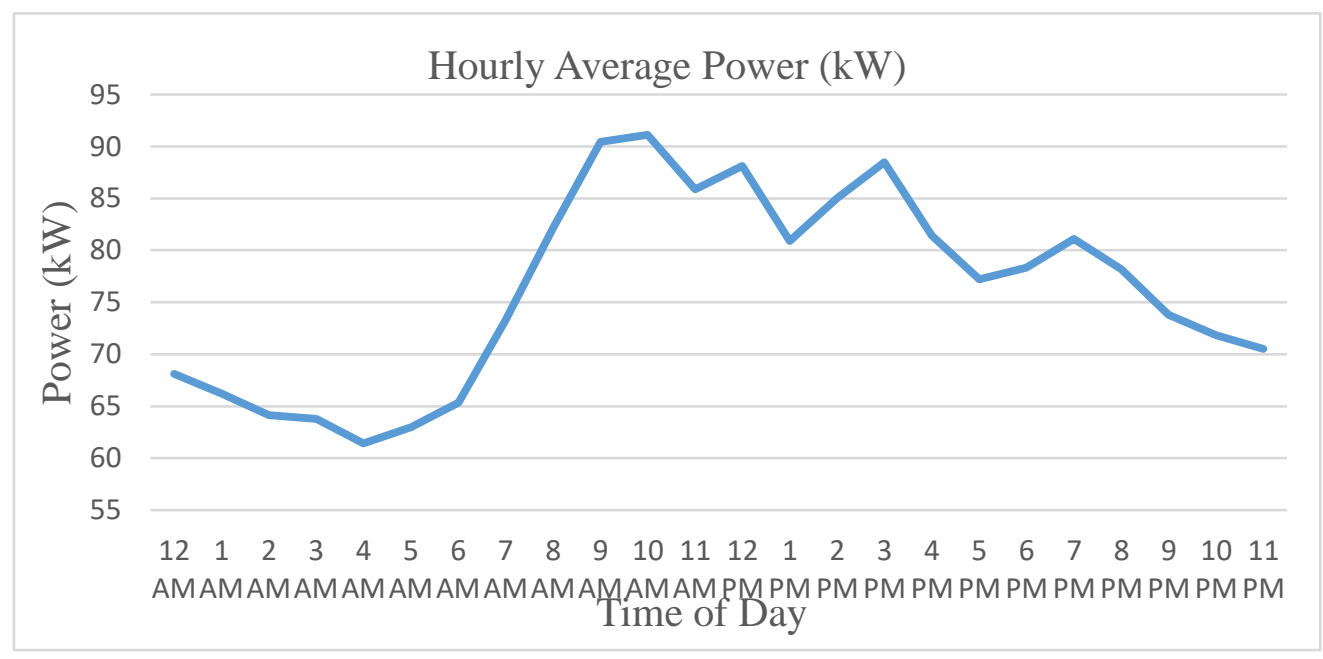

Figure 1: Daily Load Profile for the site. 
Rotich et al., Adv. J. Grad. Res.; Vol. 5, Issue 1, pp: 33-42, January 2019

The peak load was found to be $177 \mathrm{~kW}$, base load was found to be $60 \mathrm{~kW}$. The daily average energy usage was found to be $1864.28 \mathrm{kWh}$. Further analysis of the power consumption data revealed that daytime usage is $58 \%$ of total daily consumption while for nighttime consumption is $42 \%$.

\subsection{Solar PV Sizing}

Solar PV system sizing was done by choosing to meet the whole of the daytime load through Solar PV. Daytime energy demand was found to be $1080.42 \mathrm{kWh}$. Canadian Solar MaxPower CX6S 325p module rated 325Wp was selected for this application. Its technical and environmental data that affect the performance of selected PV module are given in Table 2. Figure 2 shows the daily average insolation in a TMY at the site.

Table 2: Canadian MaxPower-CS6X-325W Module Data

\begin{tabular}{|c|c|}
\hline \multicolumn{2}{|c|}{ Canadian Solar Max Power CX6S-325P } \\
\hline Parameter & Value \\
\hline Rated Power & $325 \mathrm{~W}$ \\
\hline Power Tolerance & $\pm 5 \mathrm{~W}$ \\
\hline Module Efficiency & $16 \%$ \\
\hline NOCT & $42 \pm 2{ }^{\circ} \mathrm{C}$ \\
\hline Derating Factor & $88 \%$ \\
\hline \multicolumn{2}{|}{ *Electrical Data at STC } \\
\hline
\end{tabular}

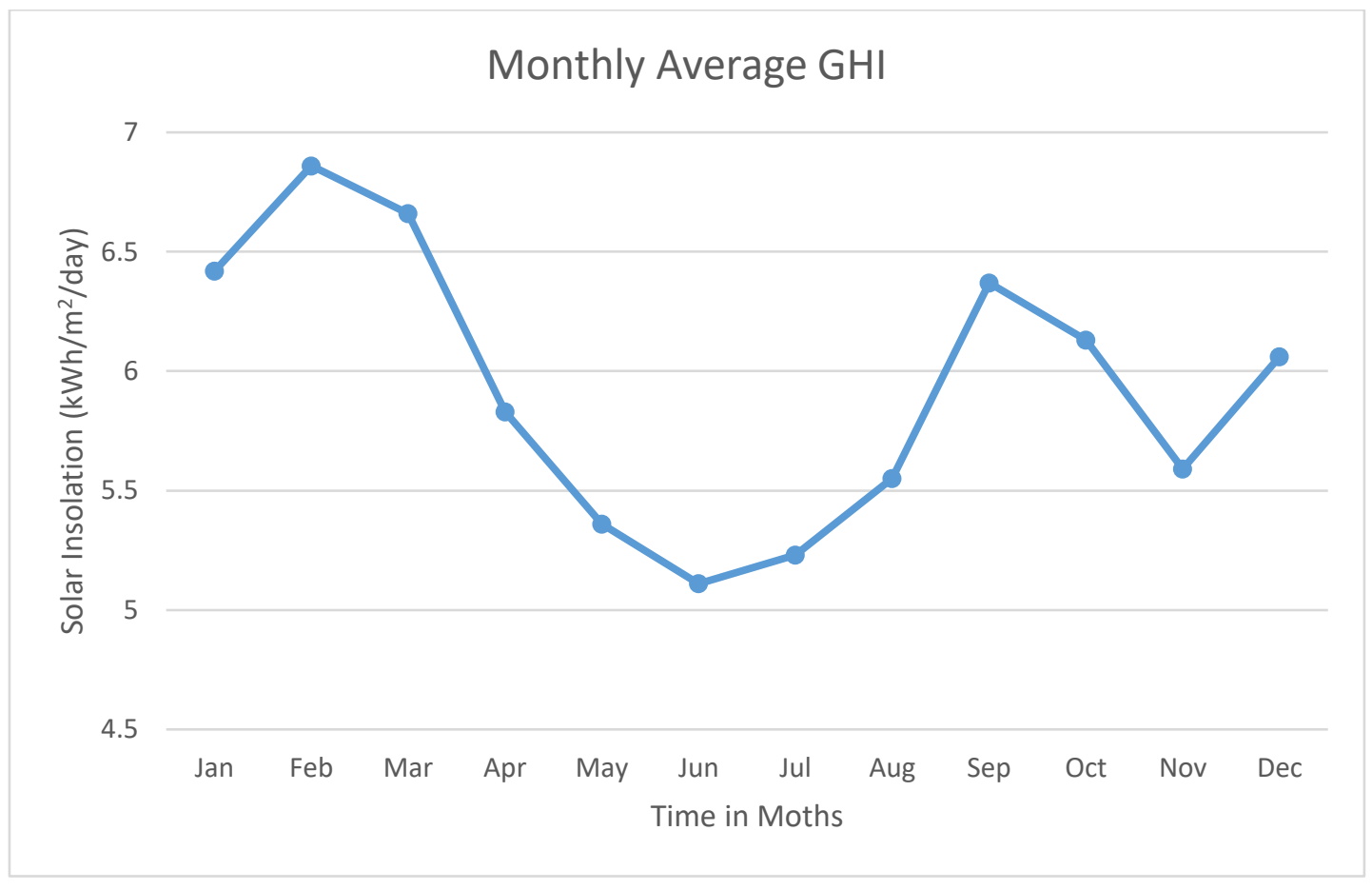

Figure 2: Global Horizontal Insolation for EASA, courtesy of NASA. [13]

By using average daily insolation of $5.93 \mathrm{kWh} / \mathrm{m}^{2}$ and the overall PV derating factor of $88 \%$, the required installed capacity of Solar PV to meet daytime energy demand was found to be $207 \mathrm{~kW}$. This translates to 640 CX6S-325PC modules which cost KSh 25,584,000 and an estimated annual generation of $394353 \mathrm{kWh}$. Taking operation and maintenance costs as $2 \%$ of capital cost at a discount rate of $10 \%$ gives an NPC of KSh $30,228,540$. 


\subsection{Inverter Sizing}

An Inverter needs to be sized to match the PV array ratings. The PV array ratings sized for meeting specific load is $207 \mathrm{~kW}$. Grid tie inverter (GTI) with rating of at least $210 \mathrm{~kW}$ is suitable for use to convert the PV array DC power to AC power. the inverter model that fit closest to the PV array output was found to be Soleil 220 TRL (C) rated $220 \mathrm{~kW}$. The capital cost for this inverter is KSh 2,500,000 with a lifespan of 15 years. Its specifications are shown in Table 3. Assuming operation and maintenance costs to be $2 \%$ of capital cost at discount rate of $10 \%$ gives an NPC of KSh 2,953,852. Considering inverter efficiency, AC energy output from the PV array is $383,311 \mathrm{kWh} /$ year. Total NPC for the PV system is KSh 33,182,392 while its COE is KSh $9.41 / \mathrm{kWh}$.

Table 3: Technical Data for TG750-320 STD

\begin{tabular}{|c|c|}
\hline \multicolumn{2}{|c|}{ Soleil 220 TRL Data Sheet } \\
\hline Parameter & Value \\
\hline Maximum input DC Voltage & $1000 \mathrm{~V}$ \\
\hline Maximum input DC Power & $275 \mathrm{~kW}$ \\
\hline Maximum output AC Power & $220 \mathrm{~kW}$ \\
\hline Nominal AC Voltage & $400 \mathrm{~V}$ \\
\hline Frequency & $50,60 \mathrm{~Hz}$ \\
\hline Maximum Efficiency & $97.20 \%$ \\
\hline
\end{tabular}

\subsection{Wind Turbine System Sizing}

The first step indetermining the size of a wind power generator was to identify the load to be served and the prevailing wind regime. Figure 3 shows the average monthly wind speed at the site at $30 \mathrm{~m}$. Based on the availability of wind at the site having a low diurnal pattern, wind generator is sized to meet entire daily energy demand at the site. Important wind resource parameters were used in the sizing process. These parameters are average wind speed at turbine hub height, the scale factor and the shape factor of the wind distribution at the site. As seen in Figure 3, the Wind resource potential at the site can support a wind turbine whose operating conditions are satisfactory in a low wind speed regime.

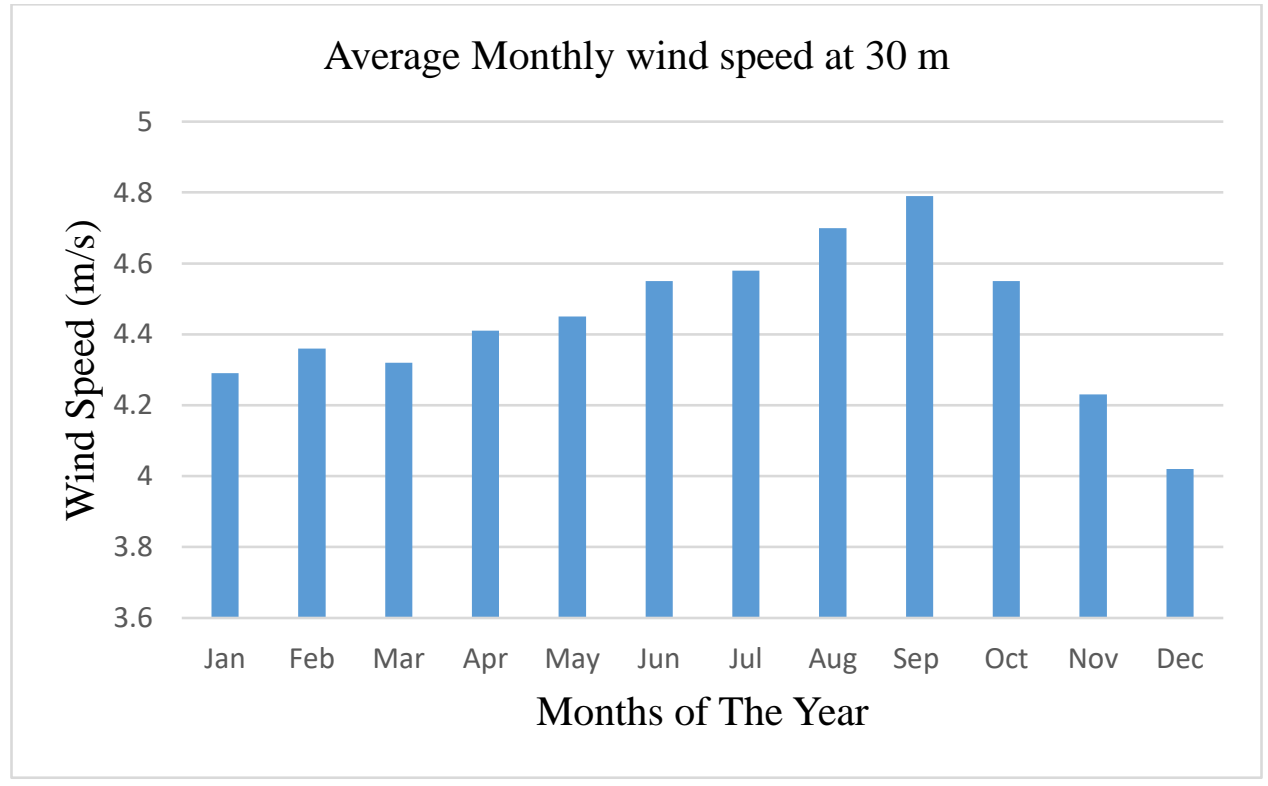

Figure 3: Wind resource potential at the site, courtesy of NASA [13] 
Using Equations 5 to calculate time fraction in a year when wind speed is equals or less the $2.5 \mathrm{~m} / \mathrm{s}$, it was estimated that productive time fraction per year is 0.7659 . Total number of hours in which a wind generator can supply power is 6709.36 . The size of wind generator was approximated by dividing annual energy demand by hours of productivity. The ideal size for meeting the load at the site was found to be $101 \mathrm{~kW}$.

Different wind turbines of ratings close to $100 \mathrm{~kW}$ were compared in order to select one that was most suitable for use at the site. Four turbines; Hummer H24.5-100 kW, ZEFIR D21-P100 kW, XANT M-21 (100 kW) and XANT M-24 (95kW). Hummer H24.5-P100 with a power rating of $100 \mathrm{kWwas}$ found to be the wind turbine that could ideally serve the power demand at the site. As can be seen in Figure 4, Hummer H24.5-P100 has the lowest cut-in wind speed of $2.5 \mathrm{~m} / \mathrm{s}$ and the highest power output at low speeds. The technical specifications for the selected Hummer H24.5-P100 rated $100 \mathrm{~kW}$ are shown in Table 4.

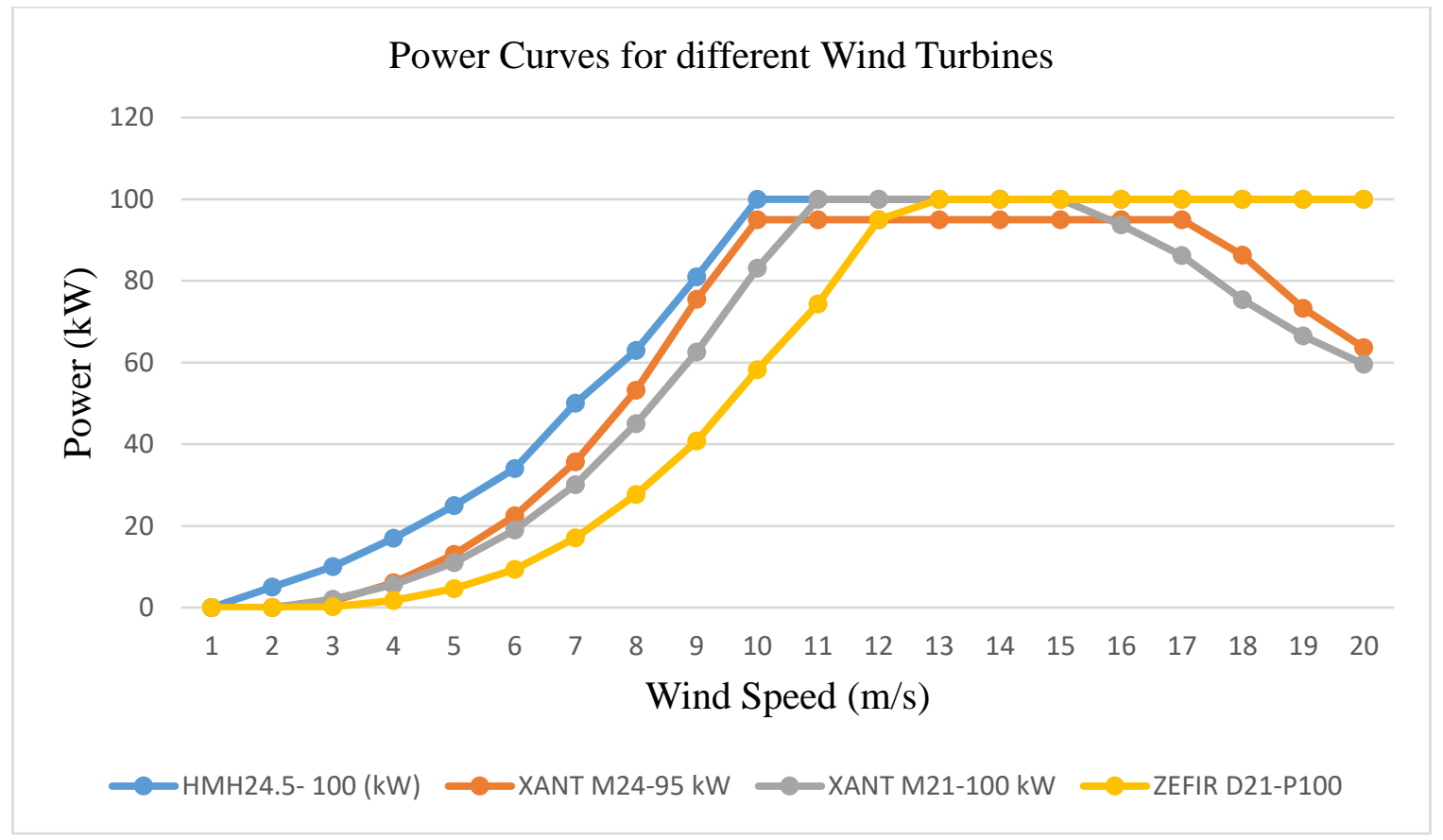

Figure 4: Power curves for different nominated wind turbines

Table 4: Data sheet for H24.5-P100

\begin{tabular}{|c|c|}
\hline \multicolumn{2}{|c|}{ Data sheet for Hummer H24.5-P100 } \\
\hline Rotor Diameter $(\mathrm{m})$ & 25 \\
\hline Blade Length $(\mathrm{m})$ & 12 \\
\hline Swept Area $\left(\mathrm{m}^{2}\right)$ & 490.27 \\
\hline Rated Power $(\mathrm{kW})$ @ $11 \mathrm{~m} / \mathrm{s}$ & 100 \\
\hline Cut-in Wind Speed $(\mathrm{m} / \mathrm{s})$ & 2.5 \\
\hline Rated Rotary Rate (revs/min) & 45 \\
\hline Working Wind Speed $(\mathrm{m} / \mathrm{s})$ & $(3-25)$ \\
\hline Survival Wind Speed $(\mathrm{m} / \mathrm{s})$ & 60 \\
\hline Hub Height $(\mathrm{m})$ & 30 \\
\hline Generator Efficiency & $>0.93$ \\
\hline Wind Energy utilization Ratio & 0.45 \\
\hline Configuration & 3 Blades, Horizontal axis, Upwind \\
\hline
\end{tabular}


Accounting for wind generator efficiency (0.4185) as described by Equation 3, the wind turbine installed capacity is modified to $241 \mathrm{~kW}$. This rounds up to 3 units of H24.5-P100 with an installed capacity of $300 \mathrm{~kW}$. In the prevailing wind regime, the wind generators are expected to supply 849,902.5 kWh/yr. (oversize of 60 $\mathrm{kW}$ due to rounding off, accounted for). The capital cost for installing the wind generators is KSh $60,000,000$. Taking O\&M costs as 2\% of capital cost at discount rate of $10 \%$ gave an NPC of KSh 70,892,448 and a COE of KSh $7.78 / \mathrm{kWh}$.

\subsection{The Grid}

The site under study is grid connected under category Commercial Industrial 1 (CI1) in a 3-Phase 4-Wire connection at $415 \mathrm{~V}$. The most significant cost for using the grid is the operation cost in the form of electricity bill which is charged under method CI1 of ERC 2013 Tariff schedules [14]. Under these schedules, this category's tariff structure consists of a fixed charge of KSh 2000, energy charge of KSh 8.70/kWh and a demand charge of KSh 800/kVA. Other variable charges and statutory levies include; fuel charge cost, foreign exchange rate, fluctuation adjustment, inflation adjustment, ERC levy, REP levy, power factor surcharge and VAT. The consolidated cost per $\mathrm{kWh}$ for this class of consumer can vary from KSh $15 / \mathrm{kWh}$ to KSh $20 / \mathrm{kWh}$ as per the fluctuation of statutory levies. Using a unit cost of energy of KSh $16 / \mathrm{kWh}$, annual operational cost for grid is KSh 10,887,395. Considering a project lifespan of 25 years, the NPC for grid is KSh98,825,320.

\subsection{Hybrid Power System Design}

The preliminary system sizing and analysis shows that Solar PV has the highest cost per unit energy while the Wind component has the lowest. An optimal HPS design should incorporate components that deliver reliable energy at all times at the lowest cost. The proposed HPS system configuration is shown in Figure 5. Further analysis for the HPS system was done using a simulation software in order to refine the constituent component as well as the overall size of the HPS.

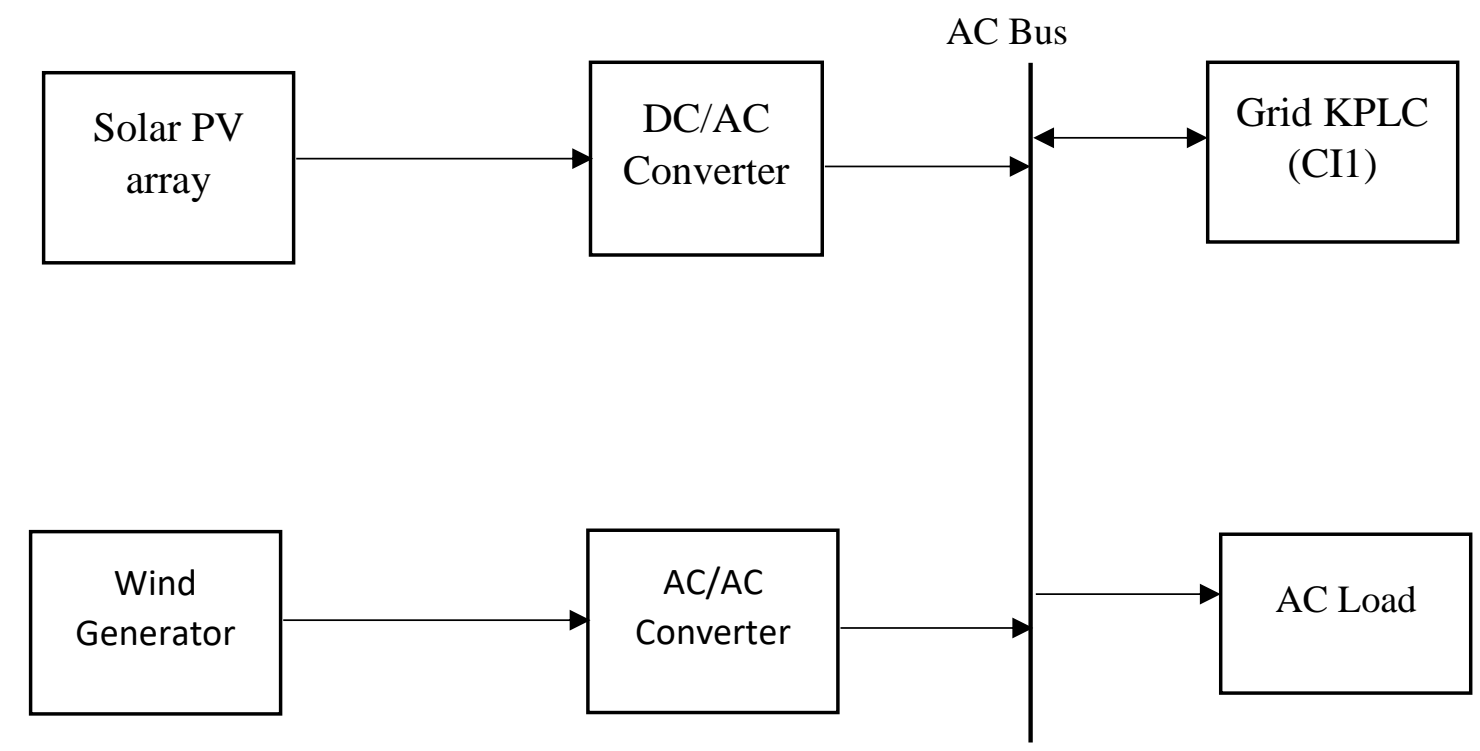

Figure 5: Hybrid Power System configuration

In order to overcome the weaknesses of individual local energy resources (solar and wind) the two are built into a hybrid power system consisting of grid as a buffering medium. Instantaneous generation and consumption are not perfectly matched hence excess generation during hours of low load conditions and shortfall during hours of low output from local energy resources must be addressed. Ideal HPS composition 
was achieved by simulating its annual operation environment. Simulation was achieved by inputting load, resources and prevailing economic constraints. The most optimal system obtained was made up of $120 \mathrm{~kW}$ solar PV, $200 \mathrm{~kW}$ wind generators and the grid. NPC and COE for this system was found to be KS 77,684,050 and KSh $8.34 / \mathrm{kWh}$ respectively. The grid plays the role of a storage medium since it is connected through net metering. A simulated system operation is shown in Figure 6. Grid sales represent the energy that is stored in the grid while imports from the grid is used to meet demand shortfall.

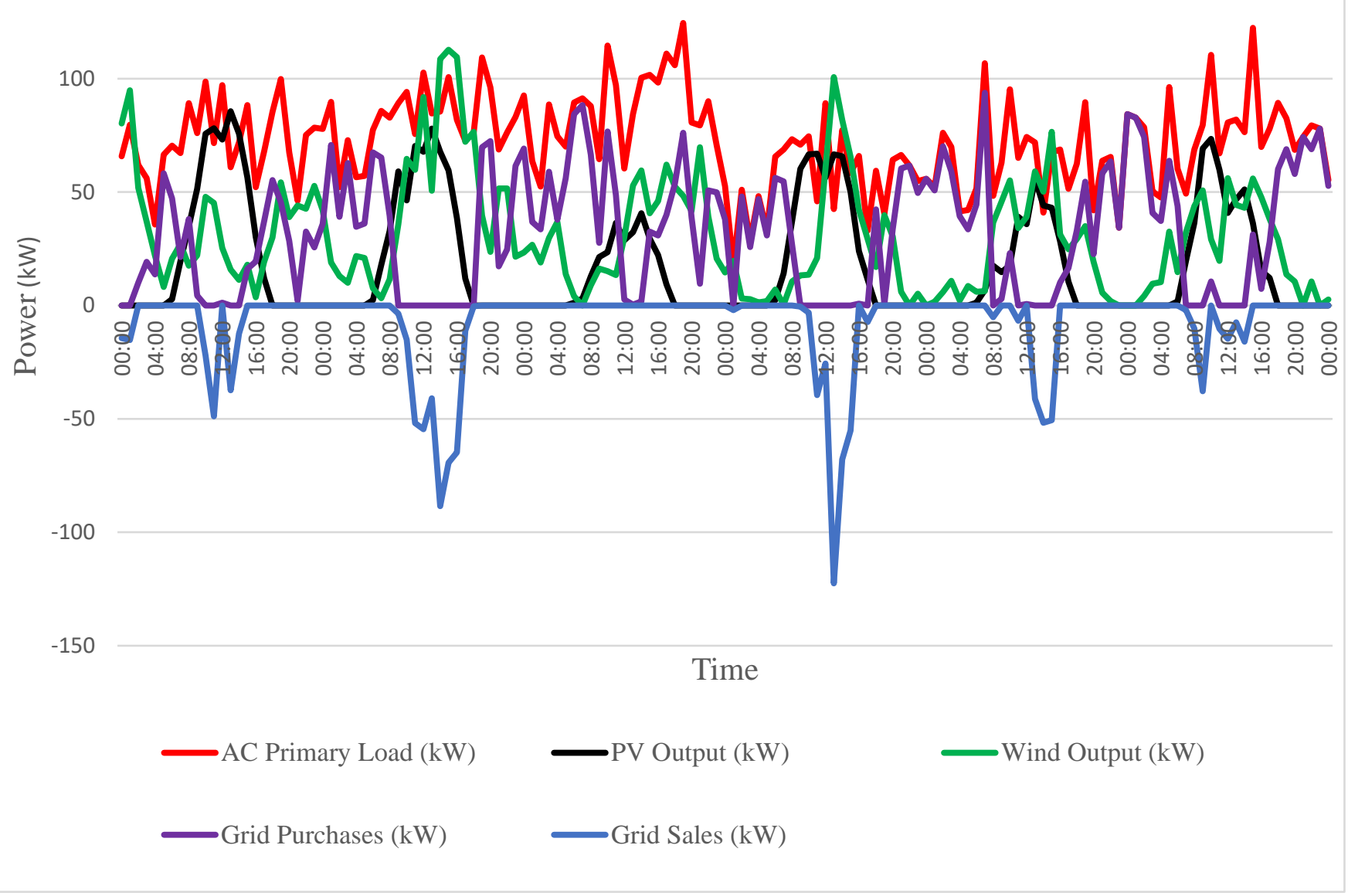

Figure 6: Simulated system performance

\section{Conclusion}

In this study, Solar PV-Wind and Grid HPS was successfully designed and sized to serve a specific load of a commercial consumer. The overall power system capacity was found to be $320 \mathrm{~kW}$ and the grid. Solar PV constitute $120 \mathrm{~kW}$ of the total capacity while wind generators is $200 \mathrm{~kW}$. The COE of the optimal HPS was found to be KSh $8.34 / \mathrm{kWh}$. This value is much lower than the prevailing grid tariff rates for this class of consumer. According to simulation results, the HPS generates a total of $868,085 \mathrm{kWh} / \mathrm{yr}$. where the wind generators contribution is $444900 \mathrm{kWh} / \mathrm{yr}$., solar PV is $205391 \mathrm{kWh} / \mathrm{yr}$. and the grid supplies $217794 \mathrm{kWh} / \mathrm{yr}$. The total consumption in this system is equal to the total generation hence there is no excess electricity generation, unmet electric load nor capacity shortage. This approach presents an outcome of a properly sized HPS and may therefore be used to design a system which is operating within similar environment. 


\section{How to Cite this Article:}

L. Rotich, J. Kamau, J. Ndeda, and R. Kinyua, "Hybrid Power System Sizing and Design for Commercial Application in Kenya", Adv. J. Grad. Res., vol. 5, no. 1, pp. 33-42, Oct. 2018. Doi: 10.21467/ajgr.5.1.33-42

\section{References}

[1] Tégani, A. Aboubou, M.Y. Ayad, M. Becherif, R. Saadi, and O. Kraa, (2014). "Optimal sizing design and energy management of standalone photovoltaic/wind generator systems". Energy Procedia 50 p163 - 170. View

[2] Bhandari, K. Lee, G. Lee, Y. Cho, and S.H Ahn., (2015). "Optimization of Hybrid Renewable Energy Power Systems: A Review". International Journal of Precision Engineering and Manufacturing-Green Technology 2 (1), P 99-112. View

[3] Muthuvel, S.A. Daniel, S.K. Paul, (2017). "Sizing of PV array in a DC Nano-grid for isolated households after alteration in time of consumption”. Engineering Science and Technology, an International Journal 20 P1632-1641. View

[4] M. Gioutsos, K. Blok, L. Velzen, S. Moorman, (2018). "Cost-optimal electricity systems with increasing renewable energy penetration for islands across the globe". Applied energy $226 \mathrm{P} 437-449$. View

[5] Gagari D., Ramananda P. and Sudip D., (2012). "Hybrid Power Generation System". International Journal of Computer and Electrical Engineering, 4, pp 141-144. View

[6] N. Prodromidis, L. Kikareas, P. Stamatopoulou, G. Tsoumanis, F.A. Coutelieris, (2015). "Modelling and Experimental Study on Renewable Energy based Hybrid Systems". International Journal of Renewable Energy Research 5 P1187-1195. View

[7] O. Oloo, L. Olang, and J. Strobl, (2016). "Spatial Modelling of Solar Energy Potential in Kenya". International Journal of Sustainable Energy Planning \& Development 6 pp 17-30. View

[8] Gossens, (2017). "Natural resource endowment is not a strong driver of wind or PV development". Renewable Energy 113, P 1007-1018. View

[9] Sahraei S. Watson S. Sofia A. Pennes T. Buonassisi I.A. Peters, (2017). "Persistent and adaptive power system for solar powered sensors of Internet of Things (IoT)". Energy Procedia 143 P 739-741. View

[10] Kolhe, K. Agbossou, J. Hamelin and T.K. Bose, (2003). "Analytical model for predicting the performance of photovoltaic array coupled with a wind turbine in a stand-alone renewable energy system based on hydrogen”. Renewable Energy, 28 pp 727-742. View

[11] Manwell F.J., McGouan G.J., Rogers L.A., (2002).Wind energy explained theory design and application. John Wiley \& Sons Ltd., USA. View

[12] Twidell and T. Weir, (2006). Renewable Energy Resources. Taylor \& Francis 270 Madison Ave, New York, NY 10016, USA. View

[13] National Aeronautic Space Administration. (n.d). NASA Surface Meteorology and Solar Energy. View

[14] (2013). Schedule of Tariffs 2013, Nairobi: Energy Regulatory Commission. View

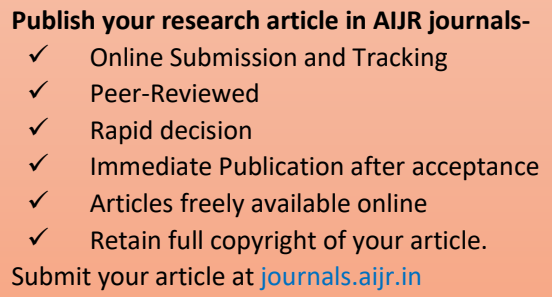

Publish your books with AIJR publisher-

$\checkmark \quad$ Publish with ISBN and DOI.

$\checkmark$ Publish Thesis/Dissertation as Monograph.

$\checkmark \quad$ Publish Book Monograph.

$\checkmark$ Publish Edited Volume/ Book.

$\checkmark$ Publish Conference Proceedings

$\checkmark \quad$ Retain full copyright of your books. Submit your manuscript at books.aijr.org 